\title{
O PROFESSOR DE MEDICINA VETERINÁRIA NA ÓTICA DE EX-ALUNOS
}

\author{
Regina Célia de Santis Feltran*
}

\section{RESUMO}

Esta é uma pesquisa de abordagem qualitativa, que se baseia nas teorias desenvolvimentistas, sobre avaliação do professor universitário na ótica de 32 ex-alunos de Medicina Veterinária, procedentes de 13 Estados brasileiros. Seu objetivo foi verificar se existem regularidades em torno das descrições do melhor professor evocado, daquele que se distingüiu dos demais, e se essas regularidades aproximam-se do que a literatura psicológica aponta conceitualmente como sabedoria. Foram utilizadas questões abertas, respondidas por escrito. Os resultados mostraram que as descrições do melhor professor apresentaram, no conjunto, elementos indicadores conceituais de sabedoria, significando que os docentes distinguem-se, pessoal e profissionalmente, na ajuda quanto ao desenvolvimento de seus alunos. Concordando com estudos na mesma temática, pode-se constatar que a validade do julgamento dos graduandos a respeito do professor permanece após o término do curso, para vários aspectos, dentre os quais a adequação de preparação, interesse, estimulação da curiosidade intelectual e atitude progressista. Esses e outros fatores descritos pelos ex-alunos compõem o perfil do professor que emana sabedoria.

PALAVRAS-CHAVE: Avaliação do professor. Sabedoria. Bom professor.

Doutora em Educação pela Universidade de São Paulo e Professor do Curso de Mestrado em Educação Superior da UNITRI (Uberlândia-MG). 


\section{ABSTRACT}

This is a qualitative approach research, based on developmental theories about the evaluation of university teachers from the point of view of 32 former students of Medicine Veterinary, coming from 13 Brazilian States. Its objective was to verify if there were regularities in the descriptions of those ones considered the best teachers, the ones who distinguished themselves from the others. It was also analyzed if these regularities are close to what the psychological literature consider as wisdom. Open questions were used and they were answered in the writing form. The results showed that, in a whole, the descriptions of the best professors presented conceptual elements indicating wisdom. It means that professors are distinguished, personally and professionally, in the way they collaborate to the development of their students. Agreeing to studies on the same theme, it was evidenced that the validity of judgment of graduate students regarding the professor remains after the end of the course, in many aspects, among which the adequacy of preparation, interest, stimulation of intellectual curiosity and progress attitude. These and other factors described by the former students compose the profile of the professor who emanates wisdom.

KEYWORDS: Evaluation of teachers. Wisdom. Good professor.

Este é um estudo sobre avaliação do professor universitário pela ótica de ex-alunos de Medicina Veterinária. Insere-se em uma pesquisa ampla a respeito da docência na educação superior - que envolveu, predominantemente, as áreas de Veterinária, Zootecnia e Agronomia - realizada a partir da coleta de dados entre os participantes de um Curso de Especialização a Distância, em instituição universitária do Triângulo Mineiro.

A avaliação do professor é uma das áreas da avaliação educacional e pode ser realizada de várias maneiras e com diferentes objetivos. Esta pesquisa avaliativa envolveu a ótica do 
ex-aluno, respondendo, em parte, ao questionamento se graduandos possuem maturidade suficiente para fazer um julgamento de tamanha dimensão.

No entendimento de Rippey (1975), a questão não se refere a aceitar ou rejeitar a visão do aluno, mas a descobrir em que aspectos o aluno pode avaliar bem e como fazer bom uso da informação por ele prestada. Na década anterior os estudos de Kerlinger (1967) e nas posteriores, os de Albanese (1989) e Lampert (1997) também se ocuparam da mesma problemática.

A ótica, ou a classificação do aluno, a despeito de críticas e questionamentos que recebe, é muito usada nos processos de avaliação do docente. Cashin, em 1995, encontrou mais de 1.500 publicações em que foi contemplada, a propósito, a visão do aluno sobre o professor.

Em 17 estudos de meta análise, COHEN (1980) constatou que a melhoria do ensino estava positivamente relacionada ao fato do professor receber as informações sobre as pontuações que os alunos faziam a seu respeito, no primeiro trimestre do curso.

Drucher e Remmers (1951) e Centra (1974), comparando a opinião de bacharéis, após dez anos de formados, com as opiniões de estudantes de graduação sobre as qualidades mais importantes de um bom professor, encontraram concordância entre os dois grupos quanto à extensão dos seguintes critérios: adequação de preparação, interesse, estimulação da curiosidade intelectual e atitude progressista. Verificaram também que as avaliações de um mesmo professor por estudantes correlacionavam-se positivamente com as de bacharéis.

Feldman (1989) demostrou também haver concordância entre as pontuações de alunos quando relacionadas às de ex-alunos, resultado que encontra respaldo em estudos de Centra (1993) e Braskamp e Ory (1994).

Cashin (1995) considerou, com base nos estudos analisados, que as pontuações de alunos são estatisticamente confiáveis, válidas e relativamente livres de distorções ou da necessidade de controle; e que o julgamento efetuado pelo graduando sobre o professor tende a permanecer depois do término do curso, quando já possui 
uma certa experiência na profissão e uma visão mais crítica e estruturada a respeito de sua formação.

Concordando com Simons (1999) e valorizando a contribuição dos estudos citados, pode-se afirmar que, se colocadas como metas a melhoria do ensino e a boa qualidade da educação, deve-se investir positivamente no envolvimento de professores e alunos.

No Brasil, estudos sobre o tema se desenvolveram por Moreira (1981), Silveira e Moreira (1984), Silveira, Moreira e Nunes (1985), Silveira (1989) e Pinent (1992 e 1994). Na área de saúde, podemos destacar o estudo de Morsoletto (2001) e o de Pereira (2003), que avaliaram a docência pela ótica de alunos, utilizando o Questionário de Avaliação de Docência (QAD), proposto e validado por Pasquali (1984).

Ampliando as pesquisas a respeito da temática, este trabalho aborda a questão sob outro enfoque, por outras lentes. Tem características diferentes dos estudos citados, no tocante ao tipo de abordagem. Optou-se pela pesquisa de caráter descritivo e interpretativo, que privilegia os diferentes significados dos depoimentos, na tentativa de caracterização do fenômeno em estudo.

O problema central da pesquisa é: A que se deve a distinção atribuída pelos profissionais veterinários a professores lembrados como importantes em suas vidas; docentes que deixaram marcas estimuladoras do desenvolvimento pessoal e profissional; que foram percebidos como líderes, tutores, conselheiros e orientadores?

Acredita-se que a razão maior do reconhecimento do aluno, a respeito do trabalho do professor, não esteja apenas no trato do conteúdo (inegavelmente importante) ou nas habilidades didáticas (igualmente importantes) ou em outros fatores isolados.

Sem descartar a importância desse conjunto, esta pesquisa tenta verificar a hipótese de que a sabedoria desses mestres, ou de parte desses mestres, explique o bom empreendimento no ensino; ou melhor, na educação, a propósito do ensino. Constata-se, de imediato, dificuldades conceituais para a explicitação do que é sabedoria e as conseqüentes limitações para a condução de pesquisas nessa direção. 
Orienta-se primeiramente pela publicação Sabedoria: uma questão milenária, uma questão actual, da Professora Helena D’orey Marchand, da Universidade de Lisboa, procurando alinhavar suas relevantes argumentações às preocupações semelhantes às de outros estudos (FELTRAN, 1990; 1999; 2002), a respeito das finalidades da Educação e do compromisso do professor em formar para a autonomia. Nesses, e particularmente em outra publicação feita em parceria (FELTRAN e PAGOTTI, 2000), evidenciou-se a grande dificuldade - até mesmo a impossibilidade teórica - do professor atingir o objetivo de contribuir para o desenvolvimento da autonomia de seus alunos, no caso de ele próprio não ter alcançado nível evolutivo superior, seja do ponto de vista intelectual, seja do ponto de vista moral.

Isso reforça a direção da hipótese levantada. Acredita-se que o melhor professor, aquele que deixou marcas positivas no crescimento do aluno e que o ajudou a se desenvolver pessoal e profissionalmente, em direção à autonomia, seja o professor sábio. Transcende a transitoriedade da situação pedagógica, embora a valorize como oportunidade para trabalhar esses objetivos, imediatos, contextuais, sociais e ainda os universais, relativos à formação do Ser.

O objetivo deste estudo é mais exploratório, que conclusivo. Pretende verificar se existem regularidades em torno das descrições que ex-alunos da Medicina Veterinária fizeram a respeito do melhor professor evocado, ou seja, daquele que se distinguiu dos demais. E se essas regularidades aproximam-se do que a literatura psicológica aponta conceitualmente como sabedoria.

\section{Método}

Trata-se de uma pesquisa avaliativa, de abordagem predominantemente qualitativa, que se desenvolveu durante os encontros presenciais de um Curso de Especialização a Distância, em Julgamento de raças zebuinas, na FAZU - Faculdade de Agronomia e Zootecnia de Uberaba - MG, na oportunidade de três turmas consecutivas, entre os anos de 2000 e 2002. 
Participaram como sujeitos 32 veterinários, sendo 28 homens e quatro mulheres. Os veterinários pesquisados estavam na faixa etária entre 21 e 60 anos, distribuídos 25 até 40 anos e 7 após os 41 anos. Procediam de 13 Estados brasileiros, representando todas as regiões geopolíticas do país, com maior freqüência dos Estados de Minas Gerais (7), Mato Grosso (5) e Mato Grosso do Sul (4); em seguida, Maranhão (3), São Paulo (3), Rio de Janeiro (2), Tocantins (2), Bahia (1), Espírito Santo (1), Goiás (1), Paraná (1), Pernambuco (1) e Rio Grande do Sul (1).

Para facilidade de localização dessas variáveis os sujeitos são indicados no texto como no exemplo: S1 (o de número 1), F (sexo feminino), 24 (anos), SP (procedente do Estado de São Paulo).

A situação favorável para a pesquisa foi especialmente possibilitada pelo fato de se tratar do encontro presencial do referido curso.

A coleta de dados ocorreu durante a disciplina Didática, que compunha o currículo do curso. Aos participantes foi solicitado o que segue:

- Descreva o seu melhor professor universitário. O que o distinguia dos demais?

- Como ele ensinava?

- Como ele avaliava seus alunos?

Os alunos dispuseram- se, de imediato, à resposta escrita, pairando um grande silêncio durante 30 ou 40 minutos na classe. Poucos escreveram apenas uma página. As descrições foram recolhidas assim que concluídas.

A organização dos dados para análise seguiram orientações da abordagem qualitativa de pesquisa e, em especial, alguns procedimentos sugeridos por Bardin (1977) a respeito da análise de conteúdo. As descrições passaram por repetidas leituras, até que fossem percebidas convergências em torno de indicadores conceituais de sabedoria.

A natureza exploratória do estudo eximiu o pesquisador da preocupação com freqüência ou com comparações. Interessava a presença ou ausência de elementos indicativos do fenômeno. Foram transcritas as partes significativas de todas as descrições feitas pelos 
profissionais veterinários. Selecionados na literatura, os indicadores do conceito em estudo, tentou-se uma aproximação entre ambos, chegando-se aos resultados que são apresentados a seguir.

\section{Resultados e discussão}

Retomando o problema central da pesquisa, são apresentados os depoimentos em que se evidencia a distinção atribuída pelos veterinários a professores muito importantes em suas vidas, que os estimularam pessoal e profissionalmente, e que foram percebidos como verdadeiros líderes, orientadores. São os seguintes:

- professores lembrados como importantes em suas vidas:

[...] outras personalidades também passaram por minha mente, mas com menos intensidade, não digo importância, mas que não me marcaram como esse professor (S1, F, 24, SP).

Acho que o melhor professor é aquele capaz de deixar ensinamentos que possam ser utilizados no decorrer da vida após se egressar de uma universidade. Essa linha de raciocínio me faz voltar de maneira muito clara à minha professora de Parasitologia I. (S13, M, 29, MA).

Hoje eu sempre o encontro em congressos e ele me apresenta com todo o orgulho a outros profissionais como sua ex-aluna e agora colega [...]. (S10, F, 28, MT).

Os ensinamentos do bom professor são usados ao longo de nossas carreiras, a postura e exemplo do bom professor nos servem de baliza ao longo de nossas vidas. (S16, M, 31, GO).

· professores "guardados" com afeto, líderes, tutores, guias, conselheiros, orientadores que deixaram marcas que são reconhecidas como estimuladoras do desenvolvimento pessoal e profissional: 
Demonstrava interesse por nossas vidas e futuro [...] foi meu conselheiro e meu tutor [...] se transforma em quase um pai, pois ele se preocupa, orienta, acalenta, mas sabe exigir (S10, F, 28, MT).

[...] desenvolvia seu trabalho como se fosse parceiro ou orientador, às vezes não ficava nítida a sua função em classe; de professor, passava a conselheiro [...] (S18, M, 31, MG).

Eu o considerava como melhor, pois ele era um líder, uma pessoa que nos transmitia confiança [...] A turma toda o considerava o melhor professor (S21, M, 33, MG).

[...] julgo este como o melhor porque toda a turma o respeitava como um mestre [...] (S8, M, 27, MS).

- professores que depois de algum tempo, ainda motivam admiração e agradecimentos espontâneos, não induzidos pela pesquisa:

Marconi marcou minha fase acadêmica como um grande mestre, com conhecimento profundo do assunto e que sabia como nos fornecer esse conhecimento nos estimulando o saber e nunca nos repreendendo ou nos fazendo sentir inferiores ou incapazes de aprender [...].

Do coração:

Obrigada Marconi! (S1, F, 24, SP).

Não foi por acaso que ele foi escolhido por unanimidade o paraninfo da turma. E, ainda mais, o nome de nossa turma teve o seu nome, acho que não preciso mais falar dessa figura fantástica que foi Dr. Sebastiãozinho, como o chamávamos (S26, M, 42, PE).

Deus lhe dê o céu, Dr. Fontes. Você merece. Suas idéias e seus conceitos prevalecem hoje e estão na parada e em evidência (S32, M, 58, MG). 
Interessante observar que são depoimentos de cidadãos desse novo século, de profissionais que convivem com a volatilidade das informações, que têm facilidade cada vez maior de acessá-las, tanto as de cunho profissional como as de outra natureza qualquer. Participam do avanço científico e tecnológico da era atual. E assistem a desvalorização da figura do professor pela concorrência desleal que faz a mídia com as agências formadoras.

Retomando a hipótese da pesquisa, são apresentados os depoimentos que concorrem para a sua verificação, ou seja, a de que a sabedoria desses mestres explicaria o bom empreendimento no ensino e na educação, a propósito do ensino. Na série de descrições a seguir, o objetivo central desse estudo foi trabalhado. Trata-se de verificar se existem regularidades em torno das descrições do melhor professor evocado e se essas regularidades aproximam-se do que a literatura psicológica aponta conceitualmente como sabedoria.

Acredito que em primeiríssimo lugar o que me encanta em sua pessoa é o seu saber, ou seja, seu conhecimento [...]. Conhecimento este que ele sabe dividir com o próximo. Talvez esta seja uma de suas maiores e melhores qualidades [...]. O seu modo de ser, agir, ensinar, me encantou. Um ser amigo, educado, culto e "louco" pelo saber [...]. Acredito que sua forma de ensinar [...] e principalmente sua sabedoria é que faz[em] a diferença com os demais professores (S1, F, 24, SP).

Prosseguindo a apresentação de resultados, lista-se os indicadores conceituais sobre sabedoria, com a indicação da fonte de onde foram extraídos.

- a sabedoria é a primeira entre as virtudes, transcende a dimensão exclusivamente cognitiva, pois que se refere ao "controle da razão e ao caráter" (PLATÃO, 1995, p. 19).

[...] Seu método de ensino se misturava com sua personalidade e o seu dia a dia. Centrado, o conhecimento 
do tema específico parecia fazer parte de sua constituição [...] (S20, M, 33, MT).

[...] De posturas sempre calmas e firmes, jeito calmo e atencioso, encantava a maior parte da turma de Medicina Veterinária do $4^{\circ}$ ano [...] (S23, M, 34, PR).

- a sabedoria se manifesta na ação que favorece "mudanças do aluno em seu sistema de valores, quanto à abertura a novas idéias e reorganização das anteriores" (PAUL, 1999, p. 45).

Dava ao aluno a liberdade de falar suas besteiras, quando acontecia dava chance para o mesmo se corrigir ensinando o certo e um dos pontos básicos era que os seus ensinamentos eram super práticos. (S32, M, 58, MG).

- a sabedoria favorece "[...] mudanças nos comportamentos, com base na auto- motivação de seus alunos" (PAUL, 1999, p. 45).

[...] Este professor "vestia a camisa" e nos ensinava, nos motivava a sermos homens e mulheres de verdade, sempre, sempre, sempre capazes [...] despertava a nossa mente a sempre explorar o nosso potencial, que por sinal é infinito [...] (S6, M, 26, BA).

Nunca ele impôs seu saber e sim, num gesto de pesquisa e práticas em laboratórios havia uma cumplicidade que nos motivou e incentivou [...] (S25, M, 39, RS).

- a sabedoria inclui o esforço em "[...] desenvolver novas capacidades nos alunos, como a de organizar o tempo e de adquirir novas técnicas de estudo" ( PAUL, 1999, p. 45).

O fato do tempo ser muito pequeno para abranger todos os assuntos (fato comum na maioria das disciplinas) o professor, de início, pediu para que os alunos indicassem os assuntos 
de maior interesse. Considero esta uma atitude muito válida em tempos de reestruturação de currículos geralmente "inchados", além de ter um caráter democrático (S 27, M, 27, MS).

[...] Seu método de ensino era simples e, acho eu, muito competente, pois em suas aulas, apesar do tema ser complexo e profundo, como é a técnica cirúrgica, ele estava sempre descontraído e contagiava a turma [...] nós sempre estávamos dispostos a enfrentar o dia a dia da técnica e com certeza contribuiu muito para nossa formação (S17, M, 31, MS).

Eu o considero o melhor professor universitário porque cumpriu o papel que deveria ser o mesmo de todos os outros professores [...] ensinar-nos práticas profissionais atuais e aplicáveis (S 21, M, 39, $R S)$.

Ele era do tipo durão e sistemático [...]. Pode ser que seu estilo não fosse dos mais modernos, porém o método de interagir a prática com a teoria dentro da medida exata, fazia com que o aluno tirasse o maior e melhor proveito da matéria [...] (S25, M, 37, MS).

- A sabedoria do professor resulta em estímulo “[...] ao desenvolvimento do pensamento crítico de seus alunos e à capacidade de compreender o porquê das dificuldades" (PAUL, 1999, p. 45).

Esse professor é aquele que, após a aula, o aluno não se sente cansado do assunto, quer debater mais sobre ele. Esse professor estimula o raciocínio sobre determinado assunto e por isso seus alunos acabam sendo mais favorecidos (S5, M, 26, MG).

Em sua forma de ensino, ao mesmo tempo em que se passava o conhecimento, passava-se o despertar de um senso crítico no aluno, de modo que este conseguia se encontrar num 
contexto real, não conseguindo se limitar apenas ao conteúdo didático (S6, M, 26, BA).

Durante as aulas percorria toda a sala, falava com todos os alunos, brincava com cada um, pesquisando o saber, a maturidade e o aprendizado de cada um [...] até no momento da avaliação do aprendizado, se houvesse dúvida do aluno ele tentava esclarecer (S22, M, 34, ES).

- a sabedoria consiste "[...] em tomar decisões sobre a própria vida e em ajudar os outros a tomar decisões" (BALTES e SMITH, 1990, p. 91).

Meu melhor professor universitário foi um grande amigo também, quando eu o encontrava fora da sala de aula sempre estava me dando força e apoiando minhas idéias quando eram boas (S3, M, 24, MT).

Ele mostrou que naquele instante era professor, mas passado algum tempo seus alunos seriam colegas de profissão e teriam nele um consultor onde poderiam recorrer sem receio de serem repreendidos e, com certeza, de terem apoio neste outro difícil momento (S22, M, 34, ES).

- a sabedoria envolve o compromisso de "[...] gerir questões sociais/ questionar assuntos de natureza espiritual e sobre si próprio" (BALTES e SMITH, 1990, p. 93).

A surpresa foi geral! Com uma postura nova para nós todos, ele iniciou o curso fora da sala de aula, procurando nos passar qual era a importância do conteúdo a ser abordado em nossa futura vida profissional. Valorizava acima de tudo as opiniões dos alunos [...]. O ensino seguia as etapas programadas anteriormente e, dada a mobilização de todos, sempre sobrava tempo para a troca de informações, debates, discussões. $\mathrm{O}$ aprendizado tornou-se coletivo e os resultados 
superaram até mesmo as expectativas do professor. Procurava nos enriquecer com assuntos gerais e ao mesmo tempo nos conscientizar sobre nossos papéis como cidadãos, profissionais e membros de uma estrutura social (S18, M, 31, MG).

- a sabedoria se relaciona à "[...] experiência, às capacidades cognitivas e de comunicação" (BRENT e WATSON, 1980, p. 141; BIRREN e FICHER, 1990, p. 321; KRAMER, 1990, p. 322)

[...] sua didática era perfeita [...] entrava sempre em sala de aula com vontade de dar aula! Isso fazia com que os alunos sempre tivessem vontade de assistir suas aulas, era a aula que menos falta tinha (S21, M, 33, MG).

Ele ensinava com muita originalidade, repassando conceitos históricos, programáticos, sempre inseridos no momento atual, com muitos exemplos e aplicações no cotidiano profissional. Fazia explicações das tentativas, erros e acertos que tinha vivenciado, para que compreendêssemos o momento e planejássemos um futuro de sucessos. Mantinha a assiduidade às suas aulas mesmo sem exigir presença, pois fazia discussões em grupos, mini-seminários e dissertações eloqüentes e profundas sobre determinado tema, que nos deixavam extasiados com a profundidade de conhecimentos aliados à simplicidade, integração, facilidade de acesso e honestidade (S23, M, 34, PR).

· a sabedoria não descarta o "[...] afeto e a sensibilidade em relação a certos indicadores eminentemente emocionais" (BRENT e WATSON, 1980, p. 144; BIRREN e FICHER, 1990, p. 323; KRAMER, 1990, p. 297).

O melhor professor universitário que tive conseguia aliar [...] humildade combinada com auto-valorização, disponibilidade total para o aluno [...]. Conseguia nos tirar o medo, nos dava confiança [...] (S6, M, 26, BA). 
- a sabedoria confere a "[...] percepção das intenções dos outros que facilita a compreensão empática" (BRENT e WATSON, 1980, p. 145; BIRREN e FICHER, 1990, p. 324; KRAMER, 1990, p. 298).

Era, [...] antes de mais nada, humano, amigo [...] sincero e honesto, pois tratava a todos de igual para igual. Muito calmo, muito observador, numa sala de aula contendo mais ou menos 80 alunos ele conhecia a todos, eram como se fossem seus filhos. No momento que algum aluno fazia algo que não agradava ele chamava a atenção de maneira muito educada, dava uma pequena lição de vida e continuava seus trabalhos de maneira que ninguém o recriminava (S26, M, 42, PE).

- a compreensão e a reciprocidade sugerem sabedoria, pois que constituem, conforme as palavras do mestre de Genebra, o método de educação para a paz (PIAGET, 1998, p.135).

Eu o considero meu melhor professor [...] pela integração e identificação com os seus alunos [...], pelo espírito de companheirismo e de compreensão, finalmente, por tratar seus alunos de maneira igualitária, sendo mestre e ao mesmo tempo colega, sem que com isso perdesse o respeito e admiração (S23, M, 34, PR).

Acho que foi o lado humano e a humildade de ensino que o distinguiram dos demais. Embora de grande sabedoria ele nos passava o seu lado de aluno e isso nos tornou iguais num objetivo que era o de saber (S25, M, 39, RS).

Nunca ele impôs seu saber e sim, num gesto de pesquisa e práticas em laboratórios havia uma cumplicidade que nos motivou e incentivou [...] (S25, M, 39, RS).

Talvez esta seja uma de suas maiores qualidades, seu saber, seu conhecimento, que sabe dividir com o próximo (S1, F, 24, SP). 
Era, em minha opinião melhor, devido a dar a impressão de sermos colegas na viagem do aprendizado e não apenas aluno-professor. Porém, sem nunca perder a autoridade e o dinamismo, conseguia desenvolver o conteúdo de forma leve e prazerosa (S20, M, 33, MT).

[...] tratava o aluno com respeito [...] conseguia nossa admiração e uma enorme empatia (S31, M, 57, TO).

O suposto "medo" que eu tinha, não era dele e sim de minha ignorância que ele desafiava ao me ensinar um assunto e tornálo tão fácil. Era difícil quando não sabíamos responder suas perguntas, pois queríamos que ele continuasse na sua "empolgação" de ensino em conjunto conosco e não se deparasse com nossa falta de conhecimento [...] (S1, F, 24, SP).

\section{Considerações finais}

Esta pesquisa confirma a posição de Rippey (1975), Kerlinger (1967), de Albanese (1989) e Lampert (1997) a respeito da importância da ótica do aluno quando se descobre os aspectos que ele pode avaliar bem; e quando se faz bom uso das informações por ele fornecidas.

Considerando que os sujeitos deste estudo são profissionais e ex-alunos, de faixas etárias correspondentes a uma extensão de quatro décadas, há inferências interessantes a partir dos resultados alcançados.

A primeira delas é a de que a avaliação positiva desses professores, eivada de indicadores de sabedoria, tenha permanecido desde a graduação, na maior parte desses profissionais. Tal inferência se respalda nos estudos de Drucher e Remmers (1951), Centra (1974; 1993), Braskamp e Ory (1994), bem como nas conclusões do extenso levantamento feito por Cashin (1995), com base nos estudos analisados, considerando as pontuações de alunos estatisticamente confiáveis e o julgamento sobre o professor tendendo quando aqueles já possuem experiência 
na profissão e uma visão mais crítica e estruturada a respeito da própria formação. Na situação examinada, ocorreram menções explícitas de reconhecimento e até mesmo de admiração aos mestres considerados os melhores.

Pode-se ainda inferir, com base na experiência vicária que referenda a generalização naturalística nos contextos da pesquisa qualitativa (LUDKE; ANDRÉ, 1986), que os resultados deste estudo servirão a outros professores, no exercício da docência universitária, na medida em que se identificam com as situações apresentadas.

Tratando-se de menções elogiosas, o pesquisador não omitiu os nomes dos professores evocados, quando espontaneamente apareceram, compreendendo o significado desses depoimentos na avaliação de seus desempenhos tanto no plano pessoal como profissional.

De qualquer forma, como aponta a literatura consultada, podese afirmar que, se colocadas como metas a melhoria do ensino e a boa qualidade da educação, o caminho mais oportuno passa pelo envolvimento de professores e alunos (SIMONS, 1999).

Constata-se, a despeito das dificuldades conceituais e empíricas apontadas e dos limites deste estudo, que há indicadores de sabedoria nas descrições dos antigos alunos sobre a personalidade, a conduta, o método de ensino, a sistemática de avaliação, o compromisso com o ensino, dentre tantos outros fatores que foram lembrados pelos sujeitos desta pesquisa.

O magistério apresenta-se como oportunidade para o professor desenvolver-se em direção à sabedoria. São muitas as situações de embates cognitivos e morais nas interações com grande número de pessoas, principalmente com os alunos.

Quando se estuda o ensino ou a aprendizagem, pode-se compreender como se apresentam os níveis evolutivos superiores, característicos do alcance da sabedoria.

A compreensão lacunar desse conceito não deve ser impedimento aos docentes, na busca de momentos de reflexão compartilhada com os pares, quanto à sabedoria de suas decisões, condutas e práticas no magistério, sabendo que nesse âmbito se manifestam posturas e convicções e, portanto, o nível de 
desenvolvimento alcançado para a resolução das situações, na totalidade de suas vidas.

Acredita-se, a partir dos resultados alcançados, que o ensino de Medicina Veterinária possa usufruir da experiência valiosa desses mestres que atuaram e/ou atuam em 13 Estados brasileiros e que, sem o saberem, deixaram marcas significativas em seus alunos, influindo positivamente na construção de cidadãos e profissionais. Mais que isso, foram por eles evocados como os melhores.

\section{Referências}

ALBANESE, M. Rating educacional quality: factors in the erosion of professional standards. Academic Medicine, v. 74, p. 652-659, 1989.

BRASKAMP, L.A.; ORY, J.C. Assessing faculty work: enhancing individual and institucional performance. San Francisco: JosseyBass, 1994.

BALTES, P. B. e SMITH, J. Toward a psychology of wisdom and its ontogenesis. In: R. J. STENBERG (ed.) Wisdom: nature, origins and development. Cambridge University Press, 1990, p. 87-120.

BARDIN, L. Análise de conteúdo. Lisboa: Edições 70; 1977.

BIRREN, J. E. e FISHER, L. M. The elements of wisdom: overview an integration. In: R. J. STENBERG (ed.) Wisdom: nature, origins and development. Cambridge University Press, 1990, p. 317-332.

BRENT, S. B. e WATSON, D. Aging and wisdom: individual and collective aspects. Comunicação apresentada no Meeting of the Gerontological Society of America: San Francisco, 1980.

CASHIN, W.E. Students rating of teaching: the research revisited. Idea Paper 32. The Center for Faculty Evaluation and Development, Kansas State University, 1995. 
CENTRA, J. A. Reflective faculty evaluation: enhancing teaching and determining faculty effectiveness. San Francisco: Jossey-Bass, 1993.

. The relationship between student and alumni ratings or teachers. Educational and Psychological Measurement, v. 34, n. 2, SAGE Publications, p. 321- 325, 1974.

COHEN, P. Effectiveness of student-rating feedback for improving college instruction: meta- analyses of finding. Research in Higher Educational. v. 13, n. 4, Springer Netherlands, p. 321-41, 1980.

FELTRAN, R. C. de S. Orientação educacional na pré-escola. Campinas: Papirus, 1990.

. Didática do Ensino Superior. Uberaba: Faculdade de Zootecnia de Uberaba, FAZU- Editora, 1999.

FELDMAN, K. A. Instructional effectiveness of college teachers as judged by teachers themselves, curren and forme students colleagues administrators and external observers. Research in higher Education, v. 30, n. 2, p. 137-194, Springer Netherland, 1989.

FELTRAN, R. C. de S. Avaliação escolar e autonomia do estudante universitário. Educação Unisinos, v. 6, n. 11, Editora UNISINOS, p. 115-135, 2002.

PAGOTTI, A. W. Avaliação do juízo moral de universitários como contribuição à docência no ensino superior. In: FELTRAN, R. C. de S. (Org.) Avaliação na educação superior. Campinas: Papirus, 2002, p. 165-190.

KERLINGER, F. N. The factor structure and content of perceptions of desirable characteristics of teachers. Educational and Psychological Measurement, v. 27, n. 3, p. 643-656, 1967. 
KRAMER, D.A. Conceptualization wisdom: the primacy of affectcognition relations. In: R. J. STENBERG (ed.) Wisdom: nature, origins and development. Cambridge University Press, 1990, p. 279- 315.

LAMPERT, E. Avaliação do professor universitário: pressupostos teóricos e conclusões. Estudos em avaliação Educacional, n. 12, Fundação Carlos Chagas, p. 65-80, 1997.

LUDKE, M.; ANDRÉ, M. Pesquisa em Educação: abordagens qualitativas. São Paulo: EPU, 1986.

MARCHAND, H. M. D. Sabedoria: uma questão milenária, uma questão actual. Lisboa: Brotéria, 1994, n. 138, p. 247-266.

MOREIRA, M.A. Avaliação do professor pelo aluno como instrumento de melhoria do ensino universitário. In: Educação e Seleção, n. 4. Fundação Carlos Chagas, 1981.

MORSOLETTO, R. H. C. Avaliação de docência na educação superior. Uberlândia, 2001. Dissertação (Mestrado em Educação) UNIT- Centro Universitário do Triângulo, Uberlândia, 2001.

PAUL, R. Hacia una autonomia del alumno: nueva pauta para medir los logros de una institución de enseñanza abierta. In: RODRÍGUEZ, E. M. y QUINTILLÁN, M. A. (Coord.). La educación a distancia en tiempos de cambios: nuevas generaciones, viejos conflictos. Madrid: Ediciones de la Torre, p. 43-60, 1999.

PEREIRA, R. Avaliação da docência na disciplina Fisioterapia Aplicada à Pneumologia. 2003. Dissertação (Mestrado em Fisioterapia). UNIT - Centro Universitário do Triângulo, Uberlândia, 2003.

PIAGET, J. Sobre a Pedagogia: textos inéditos. Trad. Cláudia Berliner. Introdução e organização de Sílvia Parrat-Dayan e Anastásia Tryphon. São Paulo: Casa do Psicólogo, 1998. 
PINENT, C. E. D. Avaliação do professor pelo aluno: um estudo na UNISINOS. 1992. Dissertação (Mestrado em Educação), Pontifícia Universidade Católica do Rio Grande do Sul, Porto Alegre, 1992.

Avaliação do Professor pelo Aluno no Centro de Ciências Exatas da UNISINOS. Scientia.: v. 5, n. 11, p. 27-31, Porto Alegre, 1994.

PLATÃO. Diálogos. Tradução de Jaime Bruna. São Paulo: Cultrix; 1995.

RIPPEY, R. M. Student evaluations of professors: Are they of value? Journal of Medical Education, v. 50, n. 10, p. 951-58, Chicago, 1975.

SILVEIRA. F. L. Avaliação do Ensino: os enfoques objetivo e qualitativo. Educação e Seleção, n. 20, São Paulo, 1989.

SILVEIRA, F. L.; MOREIRA, M. A. Avaliação do desempenho do professor pelo aluno: evidências de validade de um instrumento. Ciência e Cultura, São Paulo, v. 36, n. 3, p. 466- 472, , 1984.

SILVEIRA, F. L.; MOREIRA, M. A.; NUNES, A.D. Avaliação do desempenho do professor pelo aluno: novas evidências da validade de um instrumento. Ciência e Cultura. São Paulo, v. 37, n. 8, p. 1237-40, 1985.

SIMONS, H. Avaliação e Reforma das Escolas. In: ESTRELA, A; NÓVOA, A. Avaliaç̃̃es em Educação: novas perspectivas. Porto: Porto Editora, 1999. 